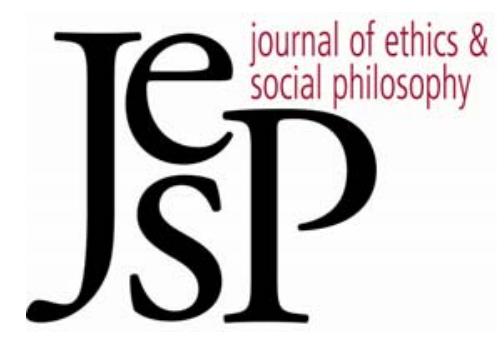

\title{
ThreE Millian Ways To Resolve OPEN Questions
}

BY ANDREW CULLISON

Journal of Ethics \& Social Philosophy

VOL. 3, NO. 1| APRIL 2009 URL: WWW.JESP.ORG COPYRIGHT (C) ANDREW CULLISON 2009 


\title{
Three Millian Ways to Resolve Open Questions \\ Andrew Cullison
}

\section{The Open Question Argument: First Version}

\author{
7 THICAL NATURALISM IS AS FOLLOWS: \\ Ethical Naturalism \\ (EN1) Each moral property is identical to some natural property. \\ (EN2) Each moral term (e.g., good) refers to some natural property \\ and has that property as its semantic content.
}

The Open Question Argument is alleged to show that if moral realism is true, then each moral property must be identical with some non-natural property and that each moral term like "good" does not have some natural property as its content.

Consider the following question schemas:

(Q1) Helping a starving child is good, but is helping a starving child $N$ ?

(Q2) Helping a starving child is good, but is helping a starving child good?

Let $N$ range over natural properties. The assumption is that for any candidate natural property for $N$, the question yielded by filling in the variable in (Q1) would always be open, whereas the question yielded by filling in the variable in (Q2) would always be closed.

What it is for a question to be open and closed is difficult to explain, and it might help if we had an example. So let's substitute pleasant-ness for $N$. We get the following two questions by filling in the variables from (Q1) and (Q2):

(Q1A) Helping a starving child is good, but is helping a starving child pleasant?

(Q2A) Helping a starving child is good, but is helping a starving child good?

Q1A and Q2A differ in cognitive significance. A reasonable person might sensibly ask Q1A. But it seems that a person could not sensibly ask Q2A. Q2A is closed in the sense that once you have made a judgment that something is good, you already have your answer to the question "Is it good?" Q1A is open in the sense that, having made a judgment about the goodness of helping the poor, you do not necessarily have an answer to that question. 
The problem for ethical naturalism is that if good-ness is identical to some natural property and "good" refers to some natural property, then if Q2 questions are closed, then Q1 questions should also be closed (once you plug in the appropriate natural property for $N$ ). However, it seems that the two could come apart. Q1A and Q2A should be the same question if ethical naturalism is true, but they are not. You have an answer to one, but not the other.

\section{The Open Question Argument}

(1) If ethical naturalism is true, then there is some natural property $\mathrm{N}$, such that schemas $\mathrm{Q} 1$ and Q2 yield the same questions.

There is no natural property $\mathrm{N}$ such that schemas Q1 and Q2 yield the same questions.

(3) Therefore, ethical naturalism is not true.

Ethical naturalism is committed to (1). If good is identical to some natural property $\mathrm{N}$ and the term "good" just means $\mathrm{N}$, then any sentence using a term $\mathrm{T}$ other than good that means $\mathrm{N}$ will express the same proposition as a sentence that substitutes $\mathrm{T}$ with good. A substitution will yield the same proposition; a substitution of terms would also yield the same question.

But in the case above we are supposed to think that they are not the same question. They are not the same question because the questions have different properties; the property being-open is had by Q1A (and not Q2A). The property being-closed is had by Q2A (and not Q1A). That is the motivation for (2). We are supposed to see that this would be true no matter what natural property we might try to identify with good; so there is no natural property $\mathrm{N}$ such that Q1 and Q2 would yield the same questions. For any natural property, there would be this difference in cognitive significance. ${ }^{1}$

\section{Ways-Millianism}

In this section I will lay out what I think is one of the best responses to the Open Question Argument. As we shall see, the Open Question Argument is

\footnotetext{
1 An aside concerning natural properties: I admit that it is still mysterious what the distinction between natural and non-natural is. Fortunately, I do not think my major criticism of the argument will rely on exactly what participants in this debate mean by natural. I am defending ethical naturalism, although I am not sure what the distinction is. I defend it because I am told that the kinds of properties that I think good might be identical to are classified as natural properties. So I am, according to many, an ethical naturalist. I can argue against Moore's Open Question Argument because it is supposed to entail that properties such as goodness and rightness could not be any of the particular properties that I think they might be. And since I do not think it will matter for the purposes of this discussion what is meant by natural, I will ignore this thorny issue.
} 
basically a kind of Frege Puzzle. Frege's Puzzles are problems for a theory in philosophy of language called Millianism. In order to address the Open Question Argument it will be helpful to briefly characterize Millianism, the primary objection to it and a Millian response. The Millian response will reveal a nice response to the Open Question Argument.

Millians endorse the classic naive theory of semantic content that the meaning of a proper name is simply its referent. Most Millians extend this to predicates and hold that predicates refer to properties (or relations) and that predicates have their referents as their content. ${ }^{2}$

Millianism faces certain problems relating to Frege's Puzzles. ${ }^{3}$ Consider the following two sentences:

(A) Mark Twain is the author of Huckleberry Finn.

(B) Samuel Clemens is the author of Huckleberry Finn.

If Millianism is correct, then (A) and (B) express the same proposition. That seems problematic. It seems obvious that (A) and (B) do not express the same proposition. While it might be easy to resist the intuition that simple sentences like (A) and (B) do not express the same proposition, the problem seems worse when we consider sentences, like the following, that contain propositional attitude verbs.

(C) Sarah believes that Mark Twain is the author of Huckleberry Finn.

(D) Sarah believes that Samuel Clemens is the author of Huckleberry Finn.

While one might simply insist that (A) and (B) express the same proposition, it seems that (C) and (D) clearly express different propositions. Surely, (C) and (D) could differ in truth value. If (C) and (D) could differ in truth value, then they do not express the same proposition. If (C) and (D) do not express the same proposition, then neither do (A) and (B). Millians have a problem.

\footnotetext{
2 We can characterize the full Millian view with the following four theses: (M1) Words have contents. The content of a name is the object to which the name refers. The content of a predicate is a property or relation. (M2) Sentences have contents. The content of a sentence is a proposition, which is also what the sentence semantically expresses. (M3) Propositions have constituents. If a sentence $\mathrm{S}$ expresses a proposition $\mathrm{P}$, then the constituents of $\mathrm{P}$ are the contents of the words that appear in S. (M4) If a person assertively utters a sentence, then she asserts the proposition that the sentence expresses. If she believes what she says, then she believes the proposition that the sentence expresses. I take the preceding four theses from Braun (2002), p. 65. In this paper he refers to the view as Naïve Russellianism, which is arguably a more appropriate term. Millianism is traditionally a thesis that just concerns the semantic content of proper names. Naïve Russellianism extends this to predicate terms and adds on the Russellian thesis about the nature of propositions.

${ }^{3}$ For a more developed discussion of Frege's Puzzles, see Salmon (1986), Braun (2000) and Braun (2001).
} 
A nice way to solve this problem is to invoke ways of believing. The solution takes belief to be a mediated relation. The belief relation is still a relation between a person and a proposition; however, persons believe propositions via some way of believing. A person believes a proposition in virtue of standing in some psychological relation to some third thing.

One theory of what ways are holds that ways are sentence-like mental representations. According to this theory, people believe propositions in virtue of standing in some relation to these representations. Let's call this relation that a person bears to the sentence-like mental representation the accepting relation. So a person believes a proposition $\mathrm{P}$ by accepting a sentencelike mental representation that semantically expresses P. ${ }^{4}$

Call the combination of this metaphysics of belief with Millianism, $W$ aysMillianism. Ways-Millianism can explain why we have the intuition that (C) and (D) could differ in truth value. Consider Sarah again. She could believe Mark Twain is the author of Huckleberry Finn by accepting the mentalese sentence "Mark Twain is the author of Huckleberry Finn." However, she could fail to accept the mental sentence "Samuel Clemens is the author of Huckleberry Finn." We could say that Sarah believes Mark Twain is the author of Huckleberry Finn - in the Twain Way - but fails to believe Mark Twain is the author of Huckleberry Finn - in the Clemens Way. Since Sarah could believe the same proposition in one way and fail to believe it in another way, it is easy to see how we might have the intuition that (C) and (D) could differ in truth value. We imagine Sarah accepting a sentence like "Mark Twain is the author of Huckleberry Finn," so we think (C) could be true. However, we think that she could accept that sentence while also accepting the denial of the sentence "Samuel Clemens is the author of Huckleberry Finn," so we think that (D) could be false. However, we are simply mistaken. (C) and (D) do not differ in truth value, but it is easy to see why we might think they could.

If the Millian metaphysics of belief is correct, then the ethical naturalist can easily respond to the Open Question Argument. Before we see the response, let's recall the Open Question Argument.

\section{The Open Question Argument}

(1) If ethical naturalism is true, then for some natural property $\mathrm{N}$ schemas, Q1 and Q2 yield the same questions.

(2) There is no $\mathrm{N}$ such that schemas Q1 and Q2 yield the same questions.

(3) Therefore, ethical naturalism is not true.

Again, ethical naturalism is committed to (1). Premise (2) is motivated by the fact that filling in the variables for Q1 and Q2 would yield questions that

4 Braun (2001) suggests this theory of ways, although he argues that his defenses of Millianism do not rely on this particular theory. 
differ in cognitive significance, and that fact is supposed to be sufficient reason to think that the questions are different.

However, if the metaphysics of belief sketched above is correct, then the fact that two questions apparently differ in cognitive significance is not sufficient reason to think that the questions are different. Just as people can have a number of different ways of thinking about a particular individual like Mark Twain, people could have a number of different ways of thinking about a property like goodness. They could think about the property good-ness in-themoral-way by using the term "good" and they could think about the property good-ness in-the-natural-way by using the phrase "pleasant." ${ }_{5}$ It is then easy to see how questions and sentences with different ways of referring to the same property could seem to differ in cognitive significance. ${ }^{6}$ If this is correct, then we will have undermined the support for premise (2) in the Open Question Argument.

The above strategy looks similar to strategies that have sought to identify the mistake with the Open Question Argument as assuming that all analytical identity statements must be obvious to a speaker who understands all of the terms in the identity statement. A similar strategy would hold that there are necessarily true identity statements that are synthetic (not analytic). These strategies are similar in that they hold that some identity statements will not always, upon reflection, be immediately obvious to competent English speakers. Call this more general strategy the Non-Obvious Identities Strategy. One might think that appealing to Ways-Millianism is but one of many ways to exercise this strategy. That seems right.

Also, the idea that the Open Question Argument is some species of a Frege Puzzle and that Millianism can help respond to it is not entirely novel. Scott Soames gestures at a response to the Open Question Argument that is similar to the one I outline above, and Mark Kalderon explicitly defends the above strategy.7

What does seem to be unappreciated in the literature and something that neither Soames nor Kalderon explore is that Ways-Millianism has the resources to respond to modified versions of the Open Question Argument that it has been assumed the Non-Obvious Identity Strategy cannot respond to. The Ways-Millian has a detailed sketch of a metaphysics of belief that actually explains what it is about the way we believe propositions that enables us to employ this Non-Obvious Identity Strategy with respect to the first version of the Open Question Argument. Most traditional responses to the Open Question Argument merely assert that there are Non-Obvious Identity statements and give us examples.

${ }_{5}$ Recall that we are assuming this for the sake of discussion. The point would apply for whatever natural property one thought was identical to being-good.

6 This solution is gestured at in Soames (2003) pp. 48-49 and is explicitly endorsed by Mark Kalderon (2004).

7 See Soames (2003), pp. 48-49, and Mark Kalderon (2004), although Kalderon endorses a different Millian explanation for how to reject a premise in the Frege Puzzle. 
Also, as we shall see, a couple of versions of the Open Question Argument do not make use of identity statements, and so merely pointing out that there are Non-Obvious Identity statements is insufficient to address those worries. However, Ways-Millian, with the same metaphysics of belief appealed to in order to address the first version of the Open Question Argument, gives us all that we need in order to respond to these allegedly stronger versions of the Open Question Argument. So, Ways-Millianism is not really in conflict with the traditional strategy, but rather a way of fleshing out the details on the Non-Obvious Identity Strategy in a way that offers a nice, unified solution to all three versions of the Open Question Argument.

In the remainder of this paper, I will show how Ways-Millianism can respond to these modified versions of the Open Question Argument. But before we examine this, we should briefly examine the main alternative response to Frege's Puzzles and examine the merits of applying these responses to the Open Question Argument.

The main alternative to Millianism when dealing with Frege's Puzzles is to concede that the arguments are in fact sound and conclude that the meaning of a term is not its referent. Having rejected the naive referential theory of meaning, we are left with the main alternative which is descriptivism. ${ }^{8}$ The standard descriptivist theory of meaning is that the meaning of a proper name is some description or cluster of descriptions that the speaker associates with the name9. So, if I authoritatively associate the description "the author of Huck Finn" with "Mark Twain," then in my idiolect, "Mark Twain" means "the author of Huck Finn."

To apply this to the Open Question Argument, we would have to concede that the meaning of moral terms like "good" is not some natural property, but rather some description that the speaker associates with "good" (e.g., that which I desire to desire, or the thing that has the best consequences etc.).

There are, however, a number of problems with accepting the descriptivist response to the Open Question Argument. First, the descriptivist response simply gives up on ethical naturalism as it is stated. So, it is less of a response and more of a concession that Moore was right; the meaning of a moral term is not some natural property.

The second problem with a descriptivist treatment of the Open Question Argument is that it will be subject to any of the standard objections to descriptivist theories about names and kinds terms. It will, for example, be

\footnotetext{
8 The use of descriptivism here should not be confused with the more common usage of the term in metaethics. In metaethics, descriptivism is typically used to denote the thesis that moral predicates actually describe some feature of reality and behave like other natural predicates. They are not merely used to prescribe behavior or express a preference. This sense of descriptivism is compatible with Millianism. Descriptivism in philosophy of language is a different sort of thesis about the semantic content of a predicate.

${ }^{9}$ See David Braun (2006) or Kripke (1973) for a detailed presentation of descriptivism.
} 
subject to the same modal, semantic and epistemic objections that Kripke raised against standard descriptivist theories of meaning for proper names..$^{10}$

A descriptivist response to the Open Question Argument has particularly troubling consequences with respect to moral terms. One might think that descriptivism could be applied to just moral predicates and hope that our intuitions concerning Kripke's objections will not be as strong with respect to moral predicates, but a restricted descriptivism about moral predicates seems to fare no better than a broader descriptivist theory about kind terms. Suppose Jan, a competent speaker of English, authoritatively associates the description "desired to be desired" with the term is good. Consider the following two sentences.

(E) If X is good, then $\mathrm{X}$ is good.

(F) If $\mathrm{X}$ is good, then $\mathrm{X}$ is desired to be desired.

(E) seems to be a necessary truth and $(\mathrm{F})$ seems to be a contingent truth - so, it seems as if descriptivism about moral terms is subject to the same sorts of modal objections that a more general form of descriptivism is subject to.

Second, descriptivism about moral predicates has the counter-intuitive consequence that we may well be largely talking past one another when it comes to moral talk. Suppose a Kantian associated the description "being such that it does not treat anyone merely as a means" with the term "morally permissible" and the Utilitarian-associated "being such that there are no alternatives that would have a higher utility" with "morally permissible." Descriptivism would have to say that when these two speakers disagree, they are not having a genuine disagreement. But it seems clear that the Utilitarian and the Kantian would genuinely disagree about these matters, and that "morally permissible" does have a kind of univocal meaning.

So, a response to the Open Question Argument that adheres to the Naive Theory of Meaning is, I think, desirable. It will preserve standard ethical naturalism, it will not be subject to the problems that face the main alternative response to Frege's Puzzles and, as we shall see, it has the resources to respond to allegedly stronger versions of Moore's Open Question Argument.

Before we examine these allegedly stronger versions of the Open Question Argument, it is also worth our time considering whether the Open Question Argument really is a kind of Frege Puzzle. It has been suggested to me that

many people believe not only that there is a difference between "I know it's F, but is it good?" and "I know it's good, but is it good?," but also a difference between "I know it's F, but is it good?" and "I know it's good,

10 See David Braun (2006) for a nice explanation about how descriptivist theories for predicates are subject to the same modal, semantic and epistemic objections that Kripke presented against descriptivist theories of proper names. 
but is it F?," the former feeling more "open" than the latter. If there really is an asymmetry of some kind here, then the explanation of why doesn't fall directly out of an answer to Frege's Puzzle - and that's part of the grounds why some philosophers have thought that they detected something more to the OQA than just a Frege's Puzzle. They've believed that there was importantly something more to the "openness" of the "but is it good?" question than that of "but is it pleasant?"11

It seems that the differing in degrees of being-open does not make this any less of a Frege Puzzle. In the original Frege Puzzle, the Millian is committed to saying that two sentences express the same proposition when intuitively they do not. The reason for thinking the propositions expressed by each sentence are not the same proposition is that the propositions expressed by each sentence appear to have different properties, namely one is believed by a person, and the other is not believed by that same person. If we set up an example where it seemed that the person believed the propositions but with differing degrees of confidence, i.e., one felt more plausible to them than the other, we would still have a Frege Puzzle.

In fact, we can set up a non-moral Open Question Argument using the sentence forms in the passage above and it seems pretty clearly a kind of Frege Puzzle. Let's use an example with predicates. Suppose someone learned that woodchucks are groundhogs. Suppose that woodchucks are extensionally equivalent with groundhogs and that being-a-groundhog is the same property as being-a-woodchuck. Now consider the following two questions.

(Q5) $\mathrm{X}$ is a woodchuck, but is $\mathrm{X}$ a groundhog?

(Q6) $\mathrm{X}$ is a groundhog, but is $\mathrm{X}$ a woodchuck?

Suppose the person forgot, when they were first told woodchucks are groundhogs, that this was an identity claim. They remember that anything that is a woodchuck is a groundhog, but they are unsure whether woodchucks are the only things that are groundhogs.

If they were in this situation, then (Q6) would feel more open than (Q5), so there is prima facie reason to think that what is expressed by (Q5) and (Q6) are different, and prima facie reason to think that "woodchuck" and "groundhog" have different meanings even though they refer to the same property. This still seems to be a Frege Puzzle. Why? Because the central claim is the same. The central claim is that the words are not interchangeable; they are not interchangeable because there are circumstances where changing around the words seems to change the properties of the proposition being expressed.

And notice that the Ways-Millian response to this works just as well, against this Frege Puzzle, as it does against the original versions of Frege's

11 Thanks to an anonymous referee for pressing me with this point. 
Puzzles. The person has different ways of thinking about the same property and might associate different features with different ways of thinking about the same property. The different ways in which the person entertains the same property explain the difference in cognitive significance rather than a difference in the semantic content of the terms.

Something similar might be the case for persons who associate different properties with "good" and "pleasant" - if they thought that all pleasant things were good, but were not sure whether all good things were pleasant. The questions in the passage above would have a similar sort of asymmetry notice that it might have the opposite sort of asymmetry as the objector describes. "I know it's pleasant, but is it good" would likely feel less open than "I know it's good, but is it pleasant." So, I don't think we need to conclude that there is anything more going on in the case of the Open Question Argument than a standard sort of Frege Puzzle. ${ }^{12}$

Let us turn our attention to allegedly strong versions of the Open Question Argument. They do not seem to be, strictly speaking, versions that Moore presented, but they are in the spirit of the Open Question Argument. The Non-Obvious Identity Strategy is alleged to be ill-equipped to handle these objections. However, thinking about the Open Question Argument as a kind of Frege Puzzle, and thinking about the Ways-Millian response to the original version, reveals a good potential response to these allegedly stronger versions.

\section{Second Open Question Argument: Motivational Internalism}

One modified version of the Open Question Argument begins by noting that there seems to be a conceptual connection between judging that something is good and being motivated to pursue it.

As Stephen Darwall, Peter Railton and Allan Gibbard note,

Attributions of goodness appear to have a conceptual link with the guidance of action, a link exploited whenever we gloss the question "Is $\mathrm{P}$ really good" as "Is it clear that, other things being equal, we really ought to, or must devote ourselves to bringing about P?" Our confidence that the openness of the open question does not depend upon any error or oversight may stem from our seeming ability to imagine for any naturalistic property $\mathrm{R}$, clear headed beings who would fail to find appropriate reason or motive to action in the mere fact that $R$ obtains...Given this imaginative possibility, it has not been logically secured that $\mathrm{P}$ is action guiding (even if, as a matter of fact, we all do find $\mathrm{R}$ psychologically compelling). And this absence of logical or conceptual link to action shows us exactly where there is room to ask, intelligibly, whether $\mathrm{R}$ is good. ${ }^{13}$

12 Notice that Fred Feldman's recent interpretation of the Open Question Argument suggests that it really is simply a kind of Frege Puzzle. See Feldman (2005).

13 Darwall, Gibbard and Railton, 1992, pp. 117. 
To generate a version of the Open Question Argument that is suggested by the above passage, I think it would be best to first understand a view I will call Weak Motivational Internalism (WMI). ${ }^{14}$

\section{Weak Motivational Internalism}

(WMI) For any person $\mathrm{P}$, if $\mathrm{P}$ judges that $\mathrm{A}$ is good (and $\mathrm{P}$ wants to do good), then $\mathrm{P}$ is motivated to pursue $\mathrm{A}$.

Ethical naturalism is in tension with WMI. Consider your favorite candidate natural property to be identified with good-ness. I will use pleasant-ness. It is possible for someone to (a) judge that some state of affairs A is pleasant (using the word "pleasant"), (b) have a desire to do good (using the word "good"), but (c) fail to be motivated to pursue A. If ethical naturalism is true, then (for any natural property that one might try to identify with goodness) a person could satisfy the antecedent of WMI, but fail to satisfy the consequent. So, the generalization is false. ${ }^{15}$ The argument is as follows:

\section{Second Open Question Argument}

(1) If ethical naturalism is true, then WMI is false.

(2) WMI is not false.

(3) Therefore, ethical naturalism is not true.

A similar problem has been raised for Millianism concerning attitude ascriptions that involve psychological generalizations. Consider the following proposition.

(G) If a person wants Twain to autograph her book, and she believes that (if she waves, then Twain will autograph her book), then she will wave.

Of $(G)$ David Braun notes that,

(G) seems true (or at least approximately true). Yet some philosophers, such as Mark Crimmins, Mark Richard, and Michael Devitt, claim that if Russellianism were true, then $(G)$ would be false. Here is one (rough) argument for their claim. Suppose that an agent wants Twain to autograph her book, and suppose that she believes that (if she waves then Clemens will autograph her book). Then according to Russellianism, she also believes that (if she waves then Twain will autograph her book), even if she would vigorously dissent from "If I wave then Twain will autograph

${ }^{14}$ I call this Weak Motivational Internalism because it is not as strong as some theses that are traditionally called Motivational Internalism.

15 This kind of argument is suggested by Stephen Darwall (2002). 
my book." Such a person would not wave, and yet, according to Russellianism she satisfies the antecedent of $(\mathrm{G})$. So, if Russellianism were true, $(\mathrm{G})$ would be false. So, Russellianism is false. This is one version of what I shall call the Generalization Objection to Russellianism. ${ }^{16}$

What David Braun calls Russellianism I have termed Millianism. We can see that the argument David Braun considers against Russellianism is almost identical to the revised version of the Open Question Argument. It is as follows.

\section{The Generalization Objection}

(1) If Russelianism is true, then $(G)$ is false.

(2) $(G)$ is not false.

(3) So, Russellianism is not true.

One way for the Russellian to respond is to reject (2), say that $(G)$ is false, and explain away our intuition that it is true by appealing to a mismatch of ways. (G) is false, but it is only false in very weird cases where there is a mismatch of ways. This explains why we have the intuition that it is true.

There is, however, another response open to the Millian. The kinds of generalizations (like $(G)$ ) that Millianism is alleged to be in conflict with admit of exceptions.

Suppose that Williams assents to both "If I wave, then Twain will nod" and "I want Twain to nod"; so the ways in which she believes and desires the relevant propositions match. Nevertheless, she could fail to wave if, for instance, she believes that there is a more effective way to get Twain to nod than waving, or she has a strong countervailing desire not to wave, or she suddenly becomes paralyzed. So if the generalizations are true, they must be true despite certain sorts of exceptions; and the critics of Russellianism, who say the generalizations are true, must admit this. ${ }^{17}$

There are exceptions to $(G)$ if you do not specify that $(G)$ is a kind of ceterus paribus conditional. Braun notes that proponents of $(G)$ have to admit that they intend for $(G)$ to be a kind of ceterus paribus conditional. $\left(G^{\prime}\right)$ must be what they really intend to express.

$\left(G^{\prime}\right)$ If a person wants Twain to autograph her book, and she believes that (if she waves, then Twain will autograph her book), then (other things being equal) she will wave.

However, since $\left(G^{\prime}\right)$ is a ceterus paribus conditional, then it is open to the Millian to say that a mismatch-of-ways scenario is one of the bizarre

16 David Braun, 2000, p. 2.

17 David Braun, 2000, p. 13. 
circumstances where other things are not equal. If we substitute $\left(G^{\prime}\right)$ for $(G)$ in the Generalization Objection, then the Millian can reject (1).

We can say something similar when we think about moral terms and the properties they denote. Sarah can believe that something is good (in the moral way) and be motivated to pursue it. However, she could believe that something is good (in some other way) and have no motivation to pursue it.

The Millian can reject (WMI), but soften the blow by saying that the Millian is only committed to denying it in contexts where there is this weird mismatching of ways.

Another response would be to force the Weak Motivational Internalist to really acknowledge that the clause is a ceterus paribus conditional, in which case the Millian can argue that a mismatch-of-ways scenario is one of the situations in which other things are not equal.

Here is one way to force someone to acknowledge that (WMI) must be construed as a ceterus paribus conditional. It seems plausible that some people have a kind of motivational failure. They suffer some sort of severe brain trauma and something happens to the area of the brain responsible for motivation. Suppose that immediately after the trauma, a person judges that they once thought that ice cream was good and they are still inclined to judge that it is good. They could even explicitly note that they are not feeling any motivation to go get ice cream the way they once would have. It seems that this person is judging that something is good without being motivated to pursue that thing. I think this example suffices to show that a motivational internalist must admit that the principle must be some sort of ceterus paribus conditional.

So, the Millian can make a similar move to defend ethical naturalism that the Millian can make to defend Millianism. The Millian can resist and say that Weak Motivational Internalism is false and reject premise (2), but soften the blow by appealing to some sort of mismatch of ways. Or the Millian can force the Weak Motivational Internalist to admit that (MI') must be some sort of ceterus paribus conditional, in which case much more work needs to be done to show that premise (1) is true. The Millian can insist that one of the circumstances in which other things are not equal are circumstances in which there is a mismatch of ways. (1) would be false.

\section{Third Open Question Argument: Reasons Internalism}

Another argument against ethical naturalism that is in the spirit of the previous two arguments is developed by Scanlon. Scanlon notes that the open-ness of the open question has to do with the fact that, once you have made a judgment that something is good, you have thereby concluded that the thing in question is worthy of pursuit. However, this does not happen when you judge that something exemplifies some purely natural property. As he notes: 
[Questions like] "This is N, but is it good?" have an open feel. They have an open feel because when we decide that something is good, we conclude that we have reason to adopt some pro-attitude towards it, but in judging simply that it has some natural property, we have not yet formed a conclusion as to whether we have reasons to adopt such a proattitude. ${ }^{18}$

The idea seems to be that if it is true that just in virtue of judging that something is good, you thereby judge that it is worthy of pursuit and this does not hold when you judge that something is pleasant, then the property good-ness must not be identical to the property pleasant-ness. We could construct the argument as follows.

\section{Third Open Question Argument: Reasons Internalism}

(1) Judging that $\mathrm{X}$ is good involves drawing conclusions about what would be reasons for acting.

(2) Judging that $\mathrm{X}$ is $\mathrm{N}$ (for any natural property) does not involve drawing conclusions about what would be reasons for action.

(3) If (1) and (2), then the property of goodness is not identical to any natural property.

(4) Therefore, the property of goodness is not identical to any natural property.

This is slightly different from the Motivational Internalism version. The second version of the Open Question Argument we considered rested on an assumption that there is something psychologically compelling about judgments about goodness. This version rests on an assumption that there is something rationally compelling (in some epistemic sense) about those judgments. In the third version, we are concerned with epistemic issues about drawing inferences. In the second version, we were concerned with psychological issues concerning motivations.

To show how Ways-Millianism solves this, it will be helpful to explain why someone like Scanlon would suppose that the mere act of judging that something is good automatically entails that someone has concluded that the action is worthy of pursuit. It must be that he thinks that we somehow believe as a background premise that if something is good it is worth pursuing. When we judge that something is good we must implicitly go through the following inference.

\section{The Scanlon Inference}

(1) A is good.

18 Scanlon, 2000, pp. 7-8. 
(2) If something is good, then it is worthy of pursuit. (implicit)

(3) Therefore, A is worthy of pursuit.

The only way I can see why someone might think that judging that A is good involves judging that $\mathrm{A}$ is worthy of pursuit would be if they thought we all (or most all of us) have as a background implicit assumption that (2) is true. Presumably, Scanlon thinks that the inference is somehow rationally compelling, and that any rational person would (at least) implicitly make the inference.

If that is why judgments about good-ness involve conclusions about what is worthy of pursuit, then Ways-Millianism can resist the argument to ethical naturalism. We begin by noting that inferences must transmit through ways of believing. To help illustrate the account of reasonable inference I have in mind, it would be useful to have an example.

\section{Ludacris and Chris Bridges}

Suppose I was at a club in Atlanta with Ludacris, the rapper, from 10 p.m. until 2 a.m. last night. This morning I hear that the police are looking for Chris Bridges, a man they suspect of having shot someone in Florida last night at 11 p.m. I have never heard the name "Chris Bridges" in my life, but that is Ludacris' real name. I don't know that "Chris Bridges" and "Ludacris" both refer to the same person. Since I do not know this fact, there is a sense in which it would be unreasonable for me to make the following inference.

\section{The Ludacris Inference}

(1) Ludacris was in the club at midnight.

(2) If Ludacris was in the club at midnight, then Ludacris did not shoot the man.

(3) Therefore, Chris Bridges did not shoot the man.

The argument above is semantically valid, but it is not syntactically valid. Semantic validity is a property of the propositions of the argument. We can say that an argument is semantically valid just in case it is impossible for the propositions expressed by the premises to be true while the proposition expressed by the conclusion sentence is false. Syntactic validity will apply only to the sentences. If two different sentences in an argument express the same proposition, then semantic validity and syntactic validity could come apart.

Given that we believe propositions and think about the premises of an argument by standing in relation to ways or sentences, it seems that reasonable inference will have to be in some way connected to syntactic validity. Reasonable inference must transfer through ways of taking propositions. 
If we accept this distinction between syntactic and semantic validity and hold that rational inference is, at least in part, a function of syntactic validity, then the Russellian could reject premise (1) of the Third Open Question Argument and maintain that judging that something is good does not always involve drawing conclusions about what is worthy of pursuit. Only when the ways of thinking about good-ness match up in every premise of the Scanlon Inference would it be plausible to suppose that the inference is drawn. If there is a mismatch of ways, judging that something is good might not involve drawing the conclusion that the thing is worthy of pursuit. The Ludacris inference would not be rationally compelling for every rational person because of a mismatch of ways. Similarly, the Scanlon Inference is not always rationally compelling for every rational person because in some cases there is a mismatch of ways.

\section{Conclusion}

The Open Question Argument seems to be another Frege Puzzle and, while some have recognized that, it seems that Ways-Millianism can handle variants of the Open Question Argument.

It may be misleading to call the second two arguments that I examined versions of the Open Question Argument. ${ }^{19}$ However, when thinking about Moore's Open Question Argument, people have offered arguments along these lines in order to note that there are ways of capturing the spirit of Moore's objection to ethical naturalism that avoid some of the standard responses that Moore's argument cannot easily handle.

Ways-Millianism is a simple and clean picture about the semantics of proper names, predicates and sentences. I do not intend to give WaysMillianism a full defense in this paper, but what I hope to have shown is that that this picture can easily handle three major ways that the Open Question Argument has been presented in the literature. This gives us a unified way to extend the defense of ethical naturalism from the original formulation of the Open Question Argument to versions of the Open Question Argument that many have deemed to be stronger and more devastating to ethical naturalism, and this also gives us a reason to take Ways-Millianism more seriously.

It may be argued that there are non-Millian ways to handle all three versions of the Open Question Argument, and so that what I have presented here is less an indirect argument for Ways-Millianism and more just a useful illustration that not getting clear on the Frege's Puzzle issues can infect other sorts of argument.

I would be satisfied with that contribution. If what I have offered is simply a clearer way to understand what's at issue in the Open Question Argument - and helped make it clear that once we are clear about what semantic theories should say about puzzles for direct reference theory - we

${ }^{19}$ See Feldman (2005). 
will better understand the structure of the Open Question Argument and how to respond to it, then that is useful.

However, the main alternative to a Millian view is Fregean-style descriptivism. And as I noted, descriptivism about moral predicates does not necessarily fare too well. It faces some of the classic problems that descriptivism about predicates faces, but it also has some particularly surprising consequences if applied just to moral predicates. It gives up on ethical naturalism as it is traditionally formulated, and it seems to commit us to saying that we are often talking past one another in moral discourse.

So, at least the main alternative semantics to the Millian view, descriptivism, actually does not handle the Open Question Argument as well as we would like. Anyone who wants to retain ethical naturalism and avoid the problems of descriptivism about moral predicates has, I think, very good reason to take Ways-Millianism more seriously. ${ }^{20}$

Andrew Cullison

SUNY Fredonia

Department of Philosophy

cullison@fredonia.edu

${ }^{20} \mathrm{I}$ am indebted to many persons for helpful feedback on the ideas in this paper including Richard Feldman, Earl Conee, Ed Wierenga, Chris Tillman, Joshua Spencer, Carl Matheson, Rob Shaver, Hud Hudson, Ned Markosian, Daniel Howard-Snyder, Francis Howard-Snyder, Ryan Wasserman, Ty Burnes, Neil Feit, Stephen Kershnar, Dale Tuggy, Ray Belliotti, Sharon Ryan and Sarah Gerkensmeyer. Versions of this paper were presented at Western Washington University, West Virginia University, The University of Manitoba and SUNYFredonia. I am grateful to all of the participants in those sessions for their helpful feedback. 


\section{Bibliography}

Braun, David. 1993. "Empty Names.” Noûs 27: 449-469.

Braun, David. 2000. "Russellianism and Psychological Generalizations." Nô̂s. 34: 203-36.

Braun, David. 2001. "Russellianism and Prediction." Philosophical Studies. 105: 59-105.

Braun, David. 2002. "Cognitive Significance, Attitude Ascriptions and Ways of Believing Propositions." Philosophical Studies. 108: 65-81.

Braun, David. 2006. "Names and Natural Kind Terms" from Ernest Lepore and Barry Smith (eds.), Handbook of Philosophy of Language, Oxford University Press.

Feldman, Fred. 2005. "The Open Question Argument: What it Isn't, and What it Is." Philosophical Issues. 15. (ed.) by Sosa, E. and Villanueva, E. pp. 22-43.

Darwall, Steven., Gibbard, A. and Railton, Peter. 1992. "Toward fin de siecle ethics: some trends." Philosophical Review. 101: 115-189.

Darwall, Steven. 2002. "Ethical Intuitionism and the Problem of Motivation" in Stratton-Lake (ed.) 2002.

Kalderon M.E. 2004. "Open Questions and the Manifest Image.” Philosophy and Phenomenological Research. 68 (2): 251-289.

Moore, G.E. 1903. Principia Ethica. New York: Cambridge University Press.

Salmon, Nathan. 1986. Frege's Puzzle. MIT Press/Branford Books.

Salmon, Nathan. 1989. "Illogical Belief." Philosophical Perspectives. 3: 243-285.

Sayre-McCord, Geoffrey (ed.). 1988. Essays On Moral Realism. Ithaca, NY: Cornell University Press. Scanlon, T.M. 2000. What We Owe Each Other. Belknap Press.

Schafer-Landau, Russ. 2003. Moral Realism: A Defence. Oxford: OUP.

Stratton-Lake, Phillip (ed.). 2002. Ethical Intuitionism: Re-evaluations. Oxford: OUP.

Soames, Scott. 2003. Philosophical Analysis in the Twentieth Century: The Dawn of Analysis, Volume 1. Princeton, NJ: Princeton University Press. 